\title{
Carcinoid Heart Disease Without Cutaneous Flushing
}

\author{
T. B. STRETTON ${ }^{\star}$, A. M. HOLMES, AND P. HORROCKS† \\ From Manchester Royal Infirmary
}

Although the carcinoid syndrome was first reported over 30 years ago (Cassidy, 1930; Scholte, 1931), it was not widely recognized until after characterization of the different features of the syndrome some 20 years later (Rosenbaum, Santer, and Claudon, 1953; Thorson et al., 1954). The condition was fully reviewed by Thorson (1958) and carcinoid heart disease was studied in detail by Roberts and Sjoerdsma (1964).

The clinical "hallmark" of the syndrome is the cutaneous flushing attack which is said to occur in 90 per cent of patients (Snow, 1963). The absence of this feature in a patient presenting with severe right heart lesions appears to be extremely rare, if not unique, and worthy of recognition.

\section{Case Report}

Mrs. A., aged 49, had, for 12 months, been vaguely unwell and had lost $3 \mathrm{~kg}$. weight. A mild watery diarrhoea (with bowel actions 3 times each morning) had troubled her for several months and during the 4 months before presentation she had developed increasing exertional dyspnoea. Her breathlessness was not associated with wheezing and she had never experienced flushing of the skin. Ankle oedema had developed in recent weeks. She had been dysarthric and had had a mildly ataxic gait since infancy. Both parents had died young, her mother in childbirth, her father of uncertain cause; she was an only child and had no children herself. A maternal uncle suffered from a chronic neurological disability with spastic paraplegia.

On examination the skin was healthy but she was pale. There was moderate peripheral oedema. The jugular venous pulse showed a striking " $a$ " wave followed by a dominant " $V$ " wave with an amplitude suggesting tricuspid incompetence. Blood pressure was $160 / 100 \mathrm{~mm}$. Hg. The cardiac impulse was diffuse; there was a sys-

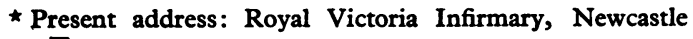
upon Tyne.

† Present address: The Royal Hospital, Sheffield. tolic thrill maximal down the left sternal edge. The heart sounds were normal; a pansystolic murmur down the left sternal edge waxed on inspiration. A soft middiastolic murmur was also present in this situation. A systolic murmur was audible in the second left interspace. The liver was greatly enlarged (below the level of the umbilicus), hard, and irregular, but showed striking systolic pulsation. Abdominal examination was otherwise normal and there was no abnormality in the respiratory system. She was dysarthric and had bilateral nystagmus; other cranial nerves were normal. There was minimal incoordination of both arms and legs with an ataxic gait. Position and vibration sensation was impaired in both legs but the sensory system was otherwise intact. Knee and ankle tendon reflexes were absent. Plantar responses were extensor. There was mild bilateral pes cavus.

Investigations. Total urinary 5-hydroxyindole excretion was $175-260 \mathrm{mg}$. $/ 24 \mathrm{hr}$. (145-165 mg./24 hr. of 5 hydroxyindole acetic acid). Normetadrenaline excretion was $0.6 \mathrm{mg} . / 24 \mathrm{hr}$. Uropepsinogen was $8 \mu \mathrm{g} . / \mathrm{hr}$. ESR $9 \mathrm{~mm}$. in 1 hour (Wintrobe). Hb $10 \mathrm{~g} . / 100 \mathrm{ml}$., MCHC 28 per cent, WBC $10,500 /$ c.mm. (normal differential count). Platelets $240,000 /$ c.mm. A sternal marrow film was of normal cellularity with changes in the erythroid series suggestive of iron deficiency. Serum albumin $4.7 \mathrm{~g} . / 100 \mathrm{ml}$; globulin $2.8 \mathrm{~g}$. $/ 100 \mathrm{ml}$.; bilirubin $0.9 \mathrm{mg} . / 100 \mathrm{ml}$; thymol turbidity 0.5 unit; alkaline phosphatase 15 units $/ 100 \mathrm{ml}$. Blood urea and serum electrolytes were normal. A 3-day collection of faeces contained $2.2 \mathrm{~g}$. fat/day; there was never any occult blood. A histamine test meal produced no free acid in the stomach. Barium studies of the gastro-intestinal tract revealed no abnormality.

A chest $x$-ray film showed cardiomegaly but was otherwise normal. An electrocardiogram showed a small secondary $\mathbf{R}$ wave in right praecordial leads and borderline abnormal right axis deviation. Cardiac catheterization confirmed the presence of pulmonary stenosis plus tricuspid incompetence and slight stenosis. The resting cardiac output was $3.5 \mathrm{l}$./min. (cardiac index $=2.43 \mathrm{l}$./ $\mathrm{min} . / \mathrm{m}^{2}$ ) with a mean pulmonary arterial pressure of $7 \mathrm{~mm}$. Hg, a $50 \mathrm{~mm}$. Hg systolic pressure gradient across 
the pulmonary valve, and a $5 \mathrm{~mm} . \mathrm{Hg}$ gradient across the tricuspid valve. Cine-angiography confirmed the presence of the valvular lesions.

Attempts to induce cutaneous flushing were unsuccessful; these included the intravenous injection of adrenaline in doses up to $20 \mu \mathrm{g}$.

Treatment and Progress. The patient was digitalized and given diuretics and ferrous sulphate. Nicotinamide was given in a dose of $50 \mathrm{mg}$. daily. The haemoglobin rose to $12 \mathrm{~g} . / 100 \mathrm{ml}$. but her general condition very slowly deteriorated. Ten months after her first attendance ascites developed. A scaly, pigmented rash appeared on her shins, suggestive of pellagra; about the same time the tongue became red and shiny and the mouth was sore. The skin lesions improved after administration of increased doses of nicotinamide $(200 \mathrm{mg}$. daily). There was no increase in the diarrhoea which was never a very troublesome feature and responded to treatment with codeine phosphate, though for a short time methysergide was given. During the later months of the illness, oedema and ascites were intractable. The serum albumin was low and the serum alkaline phosphatase rose to 68 units $/ 100 \mathrm{ml}$.

Death occurred 15 months after her first attendance and just over 2 years after onset of symptoms. At no time did cutaneous flushing occur.

At necropsy, significant abnormalities were limited to the heart, liver, and ileum, though there were bilateral pleural effusions, ascites, and peripheral oedema. The heart weighed $350 \mathrm{~g}$. The right ventricle was dilated and hypertrophied; the pulmonary valve was stenosed to $5 \mathrm{~mm}$. diameter, and there was both stenosis and incompetence of the tricuspid valve. The endocardium of the right atrium and right ventricle showed extensive patchy deposition of relatively acellular collagenous material which did not contain any elastic fibres. Similar material was seen over the distorted tricuspid valve, particularly on its ventricular aspect; other plaques engulfed the pulmonary valve and spread on to the pulmonary artery. The left atrium was normal but there was slight thickening of the chordae of the anterior mitral valve cusp.

The liver weighed $3.85 \mathrm{~kg}$. and was largely replaced by numerous metastatic deposits, many showing haemorrhage and central necrosis. Microscopically these deposits consisted of trabeculae, nests, and pseudoacini of spheroidal cells containing granular cytoplasm. The cell size was regular and there were few mitoses. A positive alkaline diazo reaction confirmed the argentaffin nature of intracellular granules which also showed characteristic yellow autofluorescence. Liver tissue at a little distance from metastases showed advanced centrilobular congestion, degeneration, and fibrosis.

A tiny, sessile tumour, $4 \mathrm{~mm}$. in diameter and deep yellow in colour on section, was present in the ileum, $8 \mathrm{ft}$. $(240 \mathrm{~cm}$.) from the ileocaecal valve. It arose from the mucosa of the antimesenteric border and there was no serosal involvement or mesenteric gland enlargement. Histologically, the tumour was encapsulated and had not penetrated the muscularis mucosae. Compact nests of regular spheroidal cells were supported by a fine vascu- lar stroma and had the staining characteristics of an argentaffin carcinoid tumour.

\section{Discussion}

The patient presented with clinical features of severe lesions of the tricuspid and pulmonary valves. At the time of diagnosis the liver was considerably enlarged and palpable nodules were present on its surface; yet the major part of the enlargement appeared to be due to venous congestion with systolic pulsation from tricuspid incompetence. Had the hepatic nodules been smaller the malignancy might have passed unrecognized initially. The importance of estimating 5-hydroxyindole acetic acid excretion in similar circumstances is obvious; this would apply in the presence of left-sided heart lesions as well as the more obvious right heart lesions, since these are present in a significant proportion of patients (Smith and Campbell, 1956; Thorson, 1958). In addition to the carcinoid syndrome the patient also had neurological disease which was believed to be a heredo-familial ataxia of the Friedreich type, despite the inadequacy of the family history. There was no evidence that the neurological features were in any way connected with the carcinoid tumour, either by virtue of altered tryptophane metabolism or as a form of "malignant neuropathy".

Right heart catheterization and angiocardiography was performed in this patient in order to investigate the haemodynamic faults as fully as possible, because it was felt that these might possibly be amenable to surgical treatment. Cardiac surgery has been attempted in an endeavour to relieve rightsided valvular stenosis in this syndrome (Wright and Mulder, 1963). Although this attempt was unsuccessful, operation could theoretically offer dramatic relief in a suitable patient and might be considered if the metastases were not advancing rapidly. Unless cardiac surgery is contemplated as a feasible therapeutic proposition, investigation of such patients by cardiac catheterization or angiocardiography appears to be unwarranted as it is not without risk, patients having died after such procedures (Biörck, Axén, and Thorson, 1952; Schwaber and Lukas, 1962).

Two features were of particular interest in this patient. One was the development of pellagra despite maintenance throughout on $50 \mathrm{mg}$. nicotinamide daily by mouth, with clearing (but not complete disappearance) of the skin lesions on a dose of $200 \mathrm{mg}$. daily. Sjoerdsma, Weissbach, and Udenfriend (1956) suggested that pellagra was due to diversion by carcinoid tissue of tryptophane metabolism, largely through the pathway which leads to production of 5-hydroxyindole acetic acid, 
resulting in deficiency of nicotinamide. Thorson et al. (1954) suggested it resulted from the diarrhoea. The fact that our patient developed pellagra while taking nicotinamide is more in favour of the latter hypothesis, though the possibility remains that there might also be increased utilization of nicotinamide by the tissues; oral supplements, if absorbed, would then be insufficient to meet total requirement.

The other interesting feature was the total absence of cutaneous flushing; nor could we induce flushing with intravenous adrenaline in doses up to $20 \mu \mathrm{g}$. One case of carcinoid syndrome without cardiac lesions described by Keen (1959) did not have spontaneous flushes but these could be induced by intravenous adrenaline (Robertson, Peart, and Andrews, 1962). The absence of flushes in our patient, despite the presumably high level of circulating serotonin, as judged by the urinary excretion of 5-hydroxyindole acetic acid, supports the view that serotonin alone is not the only humoral agent required to produce a flush. Robertson et al. (1962) showed that sympathetic amines cannot be the only endogenous trigger of flushes because phenoxybenzamine may not prevent spontaneous flushes even though it blocks flushing induced by exogenous noradrenaline. Oates et al. (1964) demonstrated that a kinin peptide was involved in the pathogenesis of the flushing attack, and it is possible that this substance was lacking, or present in insufficient concentration to produce flushing in the present case.

We wish to thank Dr. C. S. D. Don for permission to report this case.

\section{References}

Biörck, G., Axén, O., and Thorson, Å. (1952). Unusual cyanosis in a boy with congenital pulmonary stenosis and tricuspid insufficiency. Fatal outcome after angiocardiography. Amer. Heart F., 44, 143.

Cassidy, M. A. (1930). Abdominal carcinomatosis, with probable adrenal involvement. Proc. roy. Soc. Med., 24, 139.

Keen, H. (1959). Metastasizing carcinoid with diabetes mellitus. Diabetes, 8, 392.

Oates, J. A., Melmon, K., Sjoerdsma, A., Gillespie, L., and Mason, D. T. (1964). Release of a kinin peptide in the carcinoid syndrome. Lancet, 1, 514.

Roberts, W. C., and Sjoerdsma, A (1964). The cardiac disease associated with the carcinoid syndrome (carcinoid heart disease). Amer. F. Med., 36, 5.

Robertson, J. I. S., Peart, W. S., and Andrews, T. M. (1962). The mechanism of facial flushes in the carcinoid syndrome. Quart. F. Med., 31, 103.

Rosenbaum, F. F., Santer, D. G., and Claudon, D. B. (1953). Essential telangiectasia, pulmonic and tricuspid stenosis, and neoplastic liver disease. A possible new syndrome. (Abstract.) F. Lab. clin. Med., 42, 941.

Scholte, A. J. (1931). Ein Fall von Angioma telangiectaticum cutis mit chronischer Endocarditis und malignem Dünndarmcarcinoid. Beitr. path. Anat., 86, 440.

Schwaber, J. R., and Lukas, D. S. (1962). Hyperkinemia and cardiac failure in the carcinoid syndrome. Amer. f. Med., 32, 846.

Sjoerdsma, A., Weissbach, H., and Udenfriend, S. (1956). A clinical, physiologic and biochemical study of patients with malignant carcinoid (argentaffinoma). Amer. F. Med., 20, 520.

Smith, J. P., and Campbell, A. C. P. (1956). Cardiac changes associated with malignant argentaffinoma. 9 . Path. Bact., 72, 673.

Snow, P. J. D. (1963). Clinical aspects of carcinoid tumours. In The Clinical Chemistry of Monoamines p. 132. Ed. by H. Varley and A. H. Gowenlock. Elsevier, London.

Thorson, Å., Biörck, G., Björkman, G., and Waldenström, J. (1954). Malignant carcinoid of the small intestine with metastases to the liver, valvular disease of the heart (pulmonary stenosis and tricuspid regurgitation without septal defects), peripheral vasomotor symptoms, bronchoconstriction, and an unusual type of cyanosis. A clinical and pathologic syndrome. Amer. Heart $\mathcal{F}$., 47, 795.

Thorson, Å. H. (1958). Studies on carcinoid disease. Acta med. scand., Suppl. 334, 70.

Wright, P. W., and Mulder, D. G. (1963). Carcinoid heart disease: report of a case treated by open heart surgery. Amer. F. Cardiol., 12, 864. 